\title{
Una sublime devastación. Reflexiones en torno a las ruinas del siglo XX en Manufactured Landscapes (2006) de Jennifer Baichwal.
}

\author{
A sublime devastation. Thoughts about Twentieth-Century's Ruins in \\ Manufactured Landscapes (2006) by Jennifer Baichwal.
}

\author{
Natalia A. Accossano Pérez* \\ Laboratorio Texto Imagen Sociedad Universidad Nacional de Rio Negro, Consejo Nacional de \\ Investigaciones Científicas y Técnicas (ARGENTINA) \\ CE: naccos88@gmail.com / ID ORCID: 0000-0002-6990-5225
}

DOI: $10.32870 /$ sincronia.axxiv.n77.29a20

\begin{abstract}
* Licenciada en Letras de la Universidad Nacional de Río Negro (UNRN), actual Becaria doctoral de Consejo Nacional de Investigaciones Científicas y Técnicas (CONICET) de la Rep. Argentina, estudiante del doctorado en literatura de la Universidad de Buenos Aires, investigadora del Laboratorio "Texto, Imagen y Sociedad" (LabTIS) y profesora de la Sede Andina de Universidad Nacional de Río Negro
\end{abstract}

Esta obra está bajo una Licencia Creative Commons Atribución-NoComercial 4.0 Internacional

Recibido: 30/09/2019

Revisado: $16 / 10 / 2019$

Aprobado: 09/12/2019

\section{RESUMEN}

En este ensayo esbozaremos un estudio sobre una manifestación contemporánea del paisaje en ruinas: habitado por estructuras que fueron símbolo y estandarte del progreso del siglo pasado y que ahora yacen destruidas, tal como se presentan, poéticamente, en el ensayo audiovisual Manufactured Landscapes (2006); film en el que la realizadora, Jennifer Baichwal, sigue al fotógrafo Edward Burtynsky en un viaje a través de paisajes devastados por la industrialización. Nos interesa pensar este film a partir de la categoría estética de lo sublime en la Naturaleza, definida por Immanuel Kant en su Crítica 
del Juicio (1790), pero cuyas resonancias pueden rastrearse hasta la actualidad. Andreas Huyssen (2006) sostiene la apreciación estética de las ruinas ya no sería posible en la actualidad, debido a que la nuestra es una cultura que renueva y restaura, recicla o destruye. ¿De qué modo, preguntamos entonces, valoramos estéticamente las ruinas de nuestro tiempo? ¿Y cómo se presenta esta valoración en soportes audiovisuales contemporáneos?

Palabras clave: Paisaje. Ruinas. Lo sublime. Ensayo/Cine Ensayo.

\section{ABSTRACT}

In this essay we'll sketch out a research on a contemporary display of the landscape in ruins: dwelled by the skeletons which were symbol and banner of the twentieth century's progress and which now lie in pieces. This landscapes became the poetic motive of the essay-film Manufactured Landscapes (2006), in which the filmmaker Jennifer Baichwal follows the steps of the photographer Edward Burtynsky in a journey across landscapes devastated by the industrialization. We would like to see this film through the view of the aesthetic of the sublime in Nature, defined by Immanuel Kant in his Critique of Judgment (1790), but whose echoes could be traced down until our days. Andreas Huyssen (2006) believes that the aesthetic appreciation of ruins is no longer possible in our time, because ours is a culture of renewal and restoration, recycling or destruction. In which way, we wonder, do we appreciate aesthetically the ruins of our time? And in which way does this appreciation display in the contemporary audiovisual medium?

Keywords: Landscape. Ruins. The Sublime. Essay/Essay-Film.

No tengo nada que decir. Sólo que mostrar. No hurtaré nada valioso, ni me apropiaré de ninguna formulación profunda. Pero los harapos, los desechos, esos no los quiero inventariar, sino dejarles alcanzar su derecho de la única manera posible: empleándolos.

(Benjamin, 2005, p. 462) 


\section{Introducción: los jardines y las ruinas}

El profesor, novelista y ensayista Max Sebald escribió para el New York Times un artículo titulado "A Natural History of Destruction" (2002) en el que reflexiona sobre las ruinas humeantes en que se convirtieron las grandes ciudades alemanas durante la Segunda Guerra Mundial. Al inicio de este trabajo, sin embargo, Sebald recuerda su infancia en un pueblo de Bavaria que no sufrió los desastres de otras regiones, y quizás por eso, las ruinas recuperadas por la naturaleza devinieron parques de juego para los niños:

No quedaba casi nada ahora, excepto por las barandas de hierro del jardín y las bodegas. Para la década del cincuenta, el terreno, donde unos pocos árboles muy hermosos habían sobrevivido a la catástrofe, estaba completamente cubierto de maleza, y de chicos muchas veces pasábamos la tarde completa en esa espesura creada en medio del pueblo por la guerra. Recuerdo que nunca me gustó bajar por los escalones a las bodegas. Olían a humedad y putrefacción, siempre me dio miedo pisar un animal muerto o un cadáver humano (Sebald, 2002, p. 66) [traducción propia, a menos que se indique lo contrario] ${ }^{1}$.

Christopher Woodward, en su libro In Ruins (2002), también recuerda haber pasado su infancia jugando en una casa de campo abandonada, sólo que en un suburbio inglés sin rastros de la gran guerra. El autor cuenta que en su barrio la única casa de más de veinte años, Cleverdon's Stated, ya no era más que una ruina rodeada por un jardín salvaje. Cuando, veinte años más tarde, el autor regresa a visitarla, medita que lo que despierta su atracción por esos lugares abandonados es que se

1"Nothing was left of it now but its cast-iron garden railings and the cellars. By the nineteen-fifties, the plot of land, where a few handsome trees had survived the catastrophe, was entirely overgrown, and as children we often spent whole afternoons in this wilderness created in the middle of town by the war. I remember that I never felt at easy going down the steps to the cellars. They smelled of damp and decay, I always feared that Imight bump into the body of an animal or a human corpse" (Sebald, 2002, p. 66). 
constituyen como "no lugares", jardines cercados donde no entra el abrumador devenir de las sociedades que los circundan:

En las ruinas el movimiento se interrumpe y el tiempo se suspende. El puente derruido era el punto inmóvil de un mundo en plena carrera, precipitándose hacia adelante día tras día. Más allá del muro de los jardines de Cleverdon's había un mundo en el que cada día no era más que avanzar hacia un futuro más rico, más saludable, más limpio y, quizás, más feliz. Su decadente abrazo era un refugio del reloj suburbano ${ }^{2}$ (p. 36).

"El tiempo está suspendido, o revertido, o borrado; es difícil decir cuál" ${ }^{3}$ (p. 39) exclama Woodward un poco más adelante para describir la disímil percepción temporal que lo embarga al estar rodeado por ruinas. Para este autor, entonces, el modo singular en que el tiempo se detiene en estos paisajes, dejando lugar a una "quietud seductora" (seductive stillnes) más propia de los largos procesos naturales que de los humanos, es una de las características fundamentales de esta forma intervenida, inscripta, del paisaje; pero además, sostiene: "las ruinas se vuelven obra de la Naturaleza, no del hombre" ${ }^{4}$ (p. 67). En efecto, la hipótesis que guía este ensayo podría resumirse en que la potencia latente, el genius loci que habita en las ruinas y que inspiró a poetas y artistas desde el Renacimiento, reside justamente en el avance de la naturaleza sobre las estructuras abandonadas.

En su visita a la imponente ruina de las termas de Caracalla, Woodward recuerda con cierta melancolía que allí mismo, durante la primavera de 1818 -cuando el lugar abandonado se transformaba en un vergel-, el poeta romántico Percy B. Shelley compuso su Prometheus Unbound. En su prólogo, Shelley escribió:

Este poema fue escrito principalmente en las inmensas ruinas de los baños de Caracalla, entre claros llenos de flores y arboledas frondosas y fragantes que se extienden por laberintos

\footnotetext{
2 "In ruins movement is halted, and time suspended. The dilapidated bridge was the still point of a spinning world which moved foward day by day. Beyond the wall of Cleverdon's stated was a world in which every day was and advance towards a richer, fitter, cleaner and perhaps happier future. Its decaying embrace was a refuge from a suburban time-clock (Wooodward, 2002, p.36).

3 "Time is suspended, or reversed, or erased; it is hard to say which..." (Woodward, 2002, p. 39).

4 "The ruins had become a work of Nature, not man" (Woodward, 2002, p. 67).
} 
sinuosos sobre sus inmensas plataformas y arcos vertiginosos suspendidos en el aire. El cielo azul brillante de Roma y el efecto del vigoroso despertar de la primavera en este clima divino, así como la nueva vida con la que empapa a los espíritus hasta llegar incluso a la embriaguez, inspiraron esta obra dramática ${ }^{5}$ (2009, p. 18).

Casi doscientos años después, Woodward se pasea por esas mismas ruinas, devenidas atractivo turístico, en las que ya no quedan arboledas frondosas ni matas de flores fragantes, pero sí vallas y carteles y montones de personas con sus guías y sus cámaras.

Una ruina tiene dos valores [explica Woodward a un guarda que lo manda a mantenerse en el camino señalizado]. Uno objetivo como ensamblaje de ladrillos y piedras, y uno subjetivo como inspiración para los artistas. Usted puede desarraigar ese viejo árbol, superintendente, poner más vallas, rociar más herbicida, excavar y pulir. Va a preservar cada uno de los ladrillos para la posteridad, y analizar cada descubrimiento ocasional de un fragmento un poco más ornamentado en una publicación académica. Va a tener un montón impresionante de ladrillos, pero nada más. Si los arqueólogos hubiesen llegado antes que Shelley, Prometeo liberado nunca se hubiera escrito. [...] Lo que la experiencia de Shelley demuestra es que la vegetación que crece en las ruinas apela a lo profundo de nuestra conciencia, porque representa la mano del Tiempo, y la contienda entre el individuo y el universo ${ }^{6}$ (2002, p. 69).

\footnotetext{
5 "This poem was chiefly written upon the mountainous ruins of the Baths of Caracalla, among the flowery glades, and thickets of odoriferous blossoming trees, which are extended in ever winding labyrinths upon its immense platforms and the effect of the vigorous awakening spring in that divinest climate, and the new life with which it drenches the spirits even to intoxication, were the inspiration of this drama" (Shelley, 1914, p. 247).

6 "A ruin has two values. It has an objective value as an assemblage of brick and stone, and it has a subjective value as an inspiration to artists. You can uproot that alder tree, superintendente, erect more fences, spray more weed-killer, excavate and poolish. You will preserve every single brick for posterity, and analyse the very occasional discovery of a more ornamental fragment in a learned publication. You will have a great many bricks, but nothing more. If the archeologists had arrived before Shelley there would be no Prometheus Unbound. [...] What Shelley's experience shows is that the vegetation which grows on ruins appeals to the depths of our consciousness, for it represents the hand of Time, and the contest between the individual and the universe" (Woodward, 2002, p. 69).
} 
De modo similar, Francine Masiello, en su ensayo Los sentidos y las ruinas (2008), se lamenta de su devenir turístico, lo que implica que siempre exista un folleto para saber qué ver y qué pensar al respecto. Además, la autora recupera como esencial a las ruinas la presencia materializada, sensitiva, del tiem po y del relato. Para esta autora, la potencia latente de los paisajes con ruinas se encontraría en su estar entre medio: en ser un nudo entre el tiempo y el lugar, entre la naturaleza y la cultura. Eso que despierta la inspiración de los artistas, residiría en ser ese lugar donde el tiempo se manifiesta materialmente, en fragmentos inconexos de una historia que no siempre se recuerda, que no siempre puede ser contada; ahí es donde la ruina se convierte en un paisaje donde resuenan siempre muchas voces, donde el fragmento despierta la alegoría benjaminiana y el narrar fragmentario y partido, el diálogo entre la voz propia y las de los que vinieron antes que nosotros:

La ruina siempre habla de un hueco en la experiencia propia; a los gritos, declara mi incapacidad para alcanzar un pasado perdido. Entonces, a modo de compensación (pues no tengo a mi alcance otra medida posible), intento imponer mi propia experiencia sobre un pasado que nunca voy a tocar en directo. Lleno los vacíos, me hago entender con la ruina, y por último descubro a través de la ruina un despliegue temporal. Dicho de otra manera: la ruina me recuerda que siempre manejamos múltiples conceptos del tiempo. Que una temporalidad heterogénea se impone sobre la singularidad del reloj (2008, p. 101).

Por otro lado, Andreas Huyssen, en su ensayo "Nostalgia for Ruins" (2006), escribe "[...] en el cuerpo de la ruina el pasado está presente en sus residuos y aun así ya no accesible, haciendo de la ruina un disparador de la nostalgia especialmente poderoso"7 (p. 7). "Nostalgia" la añoranza de otro tiempo y de otro lugar, perdidos. Las ruinas proyectan las sombras de un pasado espléndido, pero también despiertan ecos del futuro, al modo de las profecías: así le hablaban las ruinas a Shelley, que en el avance de la primavera sobre los arcos de piedra ve la futura caída de las tiranías de su tiempo y escribe Prometeo liberado, una oda romántica al triunfo final de la libertad y la Naturaleza. Si los

7 "...in the body of the ruin the past is both present in its residues and yet no longer accesible, making the ruin an especially powerful trigger for nostalgia" (Huyssen, 2006, p. 7). 
grandes del pasado, como el emperador Caracalla, no son más que pedazos de piedra abandonados ¿qué nos queda a nosotros?

A partir de lo mencionado anteriormente, entendemos que esa potencia latente que habita en las ruinas, podría residir en la coexistencia de tres dimensiones presentes en esta forma del paisaje: en primer lugar, su adscripción (no necesaria, pero sí recurrente en la obra de nuestro corpus) a la categoría estética de lo sublime; especialmente de lo sublime como potencia destructora de la naturaleza, tal como aparece definido en la Crítica del Juicio (1790) de Immanuel Kant. En segundo lugar, la presencia de elementos culturales abandonados a una naturaleza que avanza sobre ellos, lo que genera espacios liminales donde el equilibrio entre lo cultural y lo natural se vuelca en favor de este último. En último lugar, la presencia de percepciones temporales diversas, ya que en los paisajes con ruinas coexisten un pasado histórico fragmentado, el presente de la experiencia y esta suerte de dimensión "profética", que recuerda la transitoriedad, lo perecedero de lo humano y lo natural, que siempre se renueva.

En este ensayo, a partir de los anterior, nos gustaría esbozar un estudio sobre una manifestación contemporánea de estos paisajes con ruinas; paisajes poblados de estructuras que fueron símbolo y estandarte del progreso del siglo pasado y que ahora yacen destruidas, tal como se presentan, poéticamente, en el ensayo audiovisual Manufactured Landscapes (2006), film en el que Jennifer Baichwal sigue al fotógrafo Edward Burtynsky en un viaje a través de espacios naturales devastados por el avance de la industrialización.

Huyssen, en el ensayo antes citado, sostiene que nosotros, habitantes del siglo XXI, miramos con nostalgia las ruinas del siglo pasado porque añoramos una época en la que era posible imaginar un futuro distinto ${ }^{8}$. La apreciación estética de las ruinas, para este autor, ya no sería posible en la

\footnotetext{
8 "Nostalgia is at stake in the northern transatlantic when one looks at the decaying residues of the industrial age and its shrinking cities in the industrial heartlands in Europe, the former Soviet Union, the United States, and elsewhere: [...] Such ruins and their representation in picture books, films, and exhibits are a sign of the nostalgia for the monuments of an industrial architecture of a past age that was tied to a public culture of industrial labor and its political organization. We are nostalgic for the ruins of modernity because they still seems to hold a promise that has vanished from our own age: the promise of an alternative future" (Huyssen, 2006, p. 8).
} 
actualidad, al menos no al modo que las apreciaban los modernos (como Shelley), debido a que la nuestra es una cultura que renueva y restaura, que recicla o destruye ${ }^{9}$. Y sin embargo, el ensayo audiovisual que estudiaremos en este trabajo se constituye en torno a paisajes inscriptos con ruinas. Por esta razón, nos gustaría reflexionar, aunque en el espacio de este artículo no lleguemos a una resolución, acerca de estas ruinas de nuestro tiempo, de cómo aún sirven de inspiración a los artistas con sus cámaras, de cómo es qué -si como sostiene Huyssen somos una sociedad que renueva o destruye-, estas imágenes nos interpelan tanto.

\section{Manufactured Landscapes: lo sublime y el paisaje contemporáneo}

Si vamos a hablar de la presencia de lo sublime en los paisajes inscriptos por ruinas, deberíamos comenzar por preguntarnos: ¿en qué reside esta sublimidad, dónde se encuentra? La definición que da Edmund Burke en su tratado Phlisophical Enquiry into the Origins of Our Ideas of the Sublime and Beautiful (2014) define lo sublime como una ausencia: oscuridad (ausencia de luz), silencio (ausencia de sonido), soledad (ausencia de personas). Esto es más que apropiado si pensamos en que la esencia de las ruinas se encuentra, justamente, en su fragmentariedad, es decir: en la media ausencia, el estar incompleto. Sin embargo, y por apropiada que pueda resultar esta definición para las ruinas clásicas o góticas, no ocurre lo mismo con los paisajes que protagonizan el film Manufactured Landscapes (2006) de Jennifer Baichwal. Más que ausencia lo que uno encuentra en estas ruinas es abrumadora acumulación. A lo largo de la película se suceden interminables líneas de ensamblaje, montañas de productos desechados, ladrillos, escombros, personas... amontonados hasta perder toda forma e identidad. Es por esto que nos interesa recuperar la definición de lo sublime desarrollada por Immanuel Kant (1724-1804) en la última de sus Críticas, donde las dimensiones inconmensurables cobran particular importancia.

9 "'Authentic ruins,' as they still existed un the eighteenth and nineteenth centuries, seem no longer to have a place in late capitalism's commodity and memory culture. As commodities, things in general don't age well. They become obsolete, are thrown out or recycled. Buildings are torn down or restored. The chance for things to age and to become ruins has diminished in the age of turbo capitalism, [...] The ruin of the twenty-first century is either detritus or restored age" (Huyssen, 2006, p. 10). 
Efectivamente, en su Crítica del Juicio (1790), Kant describe lo sublime como el efecto causado a un hombre que contempla en la naturaleza un fenómeno tal que fuerza a la imaginación más allá de sus límites; en este momento de inadecuación de la imaginación frente a la comprensión se podrá vislumbrar una idea de la razón, debida a una facultad suprasensible propia del sujeto. Por esto, lo sublime implicaría siempre una violencia ejercida sobre la imaginación que es forzada más allá de los límites de lo que puede ser aprehendido por los sentidos y de este modo, nunca se encuentra en la naturaleza misma sino en el hombre que la contempla:

Lo verdaderamente sublime debe buscarse solamente en el espíritu del que juzga, y no en el objeto natural cuyo juicio provoca en él ese estado de ánimo. ¿Quién calificaría de sublimes masas aún informes de montañas, en feroz desorden amontonadas unas sobre otras, con sus pirámides de hielo, o el sombrío mar proceloso? Pero el espíritu se siente realzado en su propio juicio cuando en la contemplación de esas cosas sin atender a su forma, se entrega a la imaginación y a una razón unida a ella. [...] Pero nuestra imaginación, aún en el punto culminante de su esfuerzo, revela sus límites y su inadecuación ante la comprehensión, por ella reclamada, de un objeto dado en un todo de la intuición (y, por consiguiente, para la exposición de la idea de la razón); pero muestra al propio tiempo que su destinación es obtener su adecuación a ella como a una ley. Por lo tanto, el sentimiento de lo sublime de la naturaleza es respeto hacia nuestra propia destinación (Kant, 2005, pp. 101-103).

Más adelante, el autor diferencia dos formas en las que la naturaleza puede despertar en sus espectadores este agrado negativo, que vislumbra la razón al tiempo que violenta la imaginación: lo sublime matemático y lo sublime dinámico. En cuanto al primero, Kant explica que se denomina "sublime lo absolutamente grande, [...] lo grande por encima de toda comparación" (2005, p. 92). Lo sublime matemático, entonces, se encuentra en los fenómenos de la naturaleza que despiertan la idea de infinitud; pero no la propia del razonamiento matemático, que es alcanzada progresivamente, sino lo infinito que se da de una vez, en una intuición subjetiva. En palabras de Kant:

La naturaleza es, pues, sublime en aquellos de sus fenómenos cuya intuición implica la idea de su infinidad, lo cual no puede suceder más que en virtud de lo inadecuado aún del 
máximo esfuerzo de nuestra imaginación en la estimación de la magnitud del objeto. [...] aquella magnitud de un objeto natural en que en vano emplea la imaginación toda su capacidad de comprensión, tiene que llevar necesariamente al concepto de naturaleza basada en un substrato suprasensible (al mismo tiempo fundamento de ella y de nuestra capacidad de pensar, substrato que es grande más allá de toda medida de los sentidos, y por ello no tanto permite juzgar de sublime el objeto cuanto el estado de ánimo de su estimación) (2005, p.p.100-101).

Lo sublime dinámico, por otro lado, se presenta cuando el hombre contemplativo juzga a la naturaleza como potencia; es decir, como una fuerza que supera ampliamente sus capacidades para resistirla y por eso despierta su temor. Este hombre enfrentado al poder terrible de la naturaleza, sin embargo, no debe huir aterrorizado, sino encontrar en este temor el destello de comprensión de una destinación superior a la naturaleza externa y en sí mismo. Aunque la fuerza de la naturaleza amenaza su cuerpo, no así su humanidad y en eso el hombre se juzga por sobre su potencia: supera el poder de la naturaleza no en lo que es natural en él mismo (su cuerpo) sino en lo que es sobre-natural, facultad suprasensible para juzgar.

Las rocas enhiestas que como una amenaza vemos encima de nosotros, las nubes tempestuosas que se acumulan en el cielo aproximándose con rayos y truenos, los volcanes con todo su temible poder destructivo, los huracanes con la devastación que dejan tras de sí, el ilimitado océano en cólera, la elevada catarata de un río poderoso, y otros objetos por el estilo, reducen a pequeñez insignificante, comparadas con su potencia, nuestra capacidad de resistir. Lo cual no impide que ese aspecto nos resulte tanto más atractivo cuanto más temibles sean, a condición de que podamos contemplarlos en seguridad, y solemos Ilamarlos sublimes porque exaltan las fuerzas del alma más allá de su medida media corriente, permitiéndonos descubrir en nosotros una capacidad de resistencia de índole totalmente distinta que nos da valor para podernos enfrentar con la aparente omnipotencia de la naturaleza (Kant, 2005, p. 107). 
Para Kant, no nos cansamos de repetirlo, lo sublime no se haya en la naturaleza, sino en ese placer negativo que despierta en el hombre contemplativo: un espectador privilegiado situado a segura distancia, nunca sumergido en la tempestad. Esta es la razón que lleva a Amanda Boetzkes (2010) a afirmar: "en este aspecto, la estética de lo sublime está arraigada en una determinación por ganar el 'dominio' sobre la naturaleza"10 (p. 26).Efectivamente, para Kant, lo que erróneamente se llama sublime en la naturaleza, sólo tiene como fin despertar en nosotros la seguridad de nuestra superioridad sobre ella.

Ante estas reflexiones insoslayables frente a la idea de lo sublime, cabe preguntarnos si Kant habría podido imaginar a ese hombre contemplativo, que puede intuir lo infinito y juzgarse (sino en su cuerpo, sí en su espíritu) capaz de resistir el poder de la naturaleza, como el artífice de lo sublime contemporáneo, en el que ese "dominio" del que hablara Boetzkes se expresa en una sublime devastación. Esto se debe a que nos parece posible considerar las imágenes de la naturaleza que componen Manufactured Landscapes (2006) como adscriptas, quizás pensadas, desde estas categorías de lo sublime kantiano.

Este film tiene tanto la forma de un viaje como la de una cadena de producción y destrucción, que Burtynsky y Baichwal inician en una fábrica china de productos manufacturados de dimensiones gargantuescas, donde millares de empleados trabajan con los ojos fijos y las manos ensamblando a una velocidad de vértigo. Más adelante, visitarán un pueblo asentado sobre una montaña de desperdicios tecnológicos -donde terminan su vida útil los productos de la fábrica, sólo para volver comenzar-, cuyos habitantes se afanan en reciclar componentes, aún al costo de contaminar el agua que consumen. Desde allí, se detienen en el puerto donde se construyen, a partir de trabajo precarizado, los buques mercantes que llevan materia prima de una parte a otra del mundo; y de ahí a un deshuesadero de esos mismos trasatlánticos en Bangladesh, en el que un grupo de jóvenes canta mientras arrastra inmensas placas del acero entre nubes rojas de óxido. Después de todo, aún si las hileras de trabajadores chinos llegan finalmente al otro muro y la montaña de desperdicios

10 "In this way, the sublime aesthetic is rooted in a determination to gain 'dominion' over nature" (Boetzkes, 2010, p. 26). 
tecnológicos pudiera, de algún modo, ser cuantificada ¿estas imágenes no son susceptibles de despertar en sus espectadores la intuición de lo absolutamente grande? Y aquellos diminutos soldadores colgados en las entrañas de los monstruosos barcos ¿no recuerdan al pequeño monje que pintara Friedrich frente al mar?

Además, como ya mencionamos, la película de Baichwal (2006) sigue el recorrido de Burtynsky, el fotógrafo de paisajes. Así, cada fragmento de la película es introducido por las imágenes fotográficas y por la voz de su autor, que explica su trabajo. De este modo escuchamos al propio Burtynsky contar cómo en un momento epifánico giró mal en la carretera y se encontró en medio de un paisaje violentamente inscripto por las extracciones de una mina de carbón (Baichwal, 2006, mm. 14:34-15:02). La intención de la obra que surgió a partir de este encuentro, explica, no es dilapidar a la industria, no es decir qué está mal y quién lo está haciendo mal, sino que "mis imágenes nos hacen conscientes de esos paisajes" (mm. 16:05). El fotógrafo entiende que el problema de inconexión entre el hombre y la naturaleza reside en que las personas no son conscientes de la relación entre los productos que consumen y el impacto que causa su producción en el paisaje, en los ecosistemas. En este sentido, la intención detrás de su obra sería reconstruir ese vínculo: hacernos conscientes, “mostrar la dimensión” (mm. 16:26). "Este es el paisaje de nuestro tiempo”, dice Burtynsky en la película, "una sola imagen puedes mostrar la dimensión de la destrucción” (mm. 16:23-16:26).

Mostrar en una sola imagen la dimensión de la destrucción (lo sublime matemático), mostrar lo que nos hace conscientes, tal como Burtynsky describe su obra, se relaciona con el potencial retórico de lo sublime, que prevalece desde sus primeras definiciones en la retórica clásica. Efectivamente, en el tratado del siglo I Sobre lo sublime, Pseudo-Longino escribe: "lo sublime, usado en el momento oportuno, pulveriza como el rayo todas las cosas y muestra en un abrir y cerrar de ojos y en su totalidad los poderes del orador" (1979, p. 149), lo que logra elevar al auditorio a un estado superior de comprensión. 


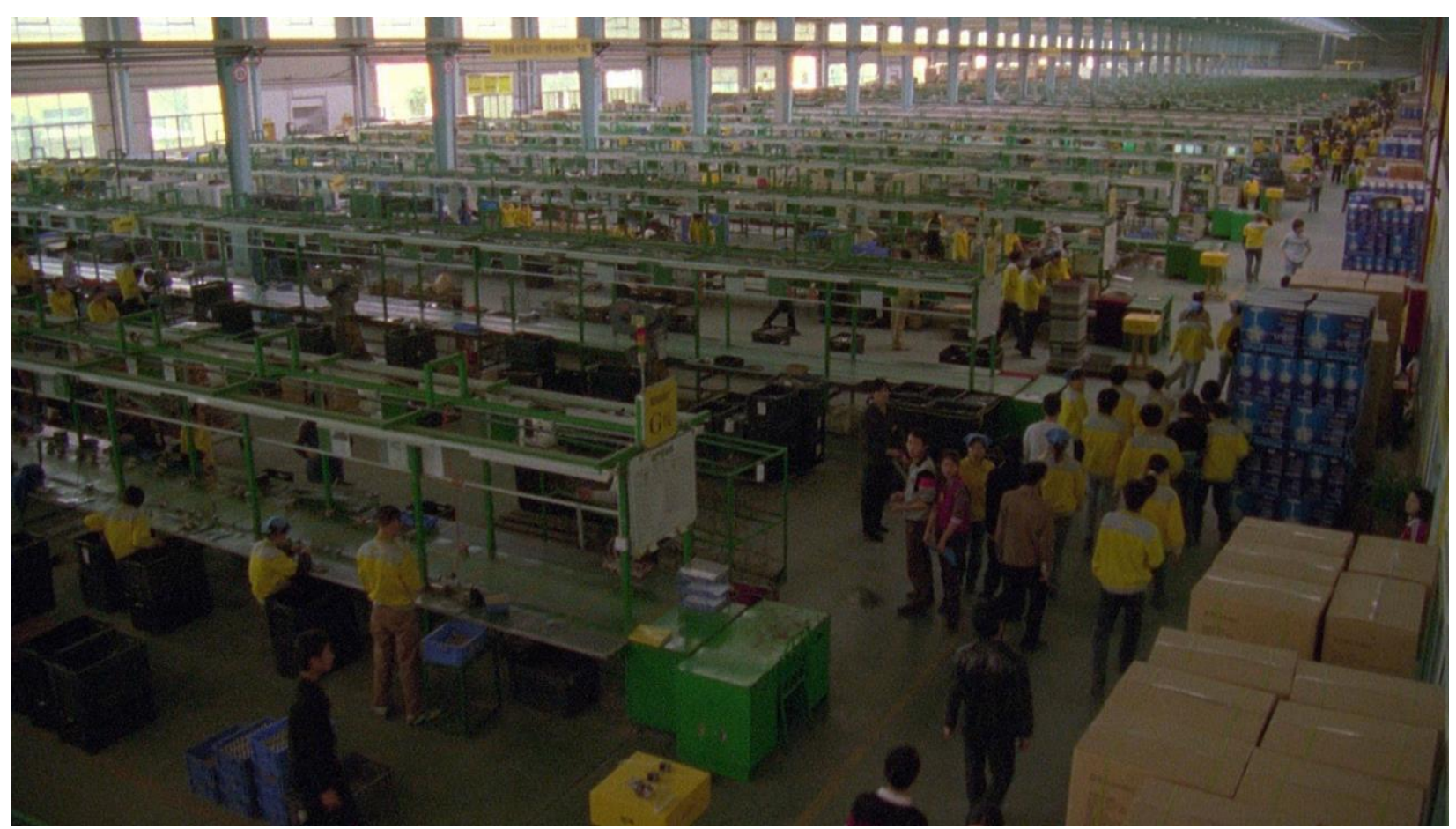

Baichwal, J. (2006), mm. 08:37 $7^{11}$.

11 Agradecemos la compañía productora de Manufactured Landscapes, Mercury Films, por cedernos los derechos para publicar estas imágenes, así como por brindarnos los fotogramas en la mejor calidad de definición. 


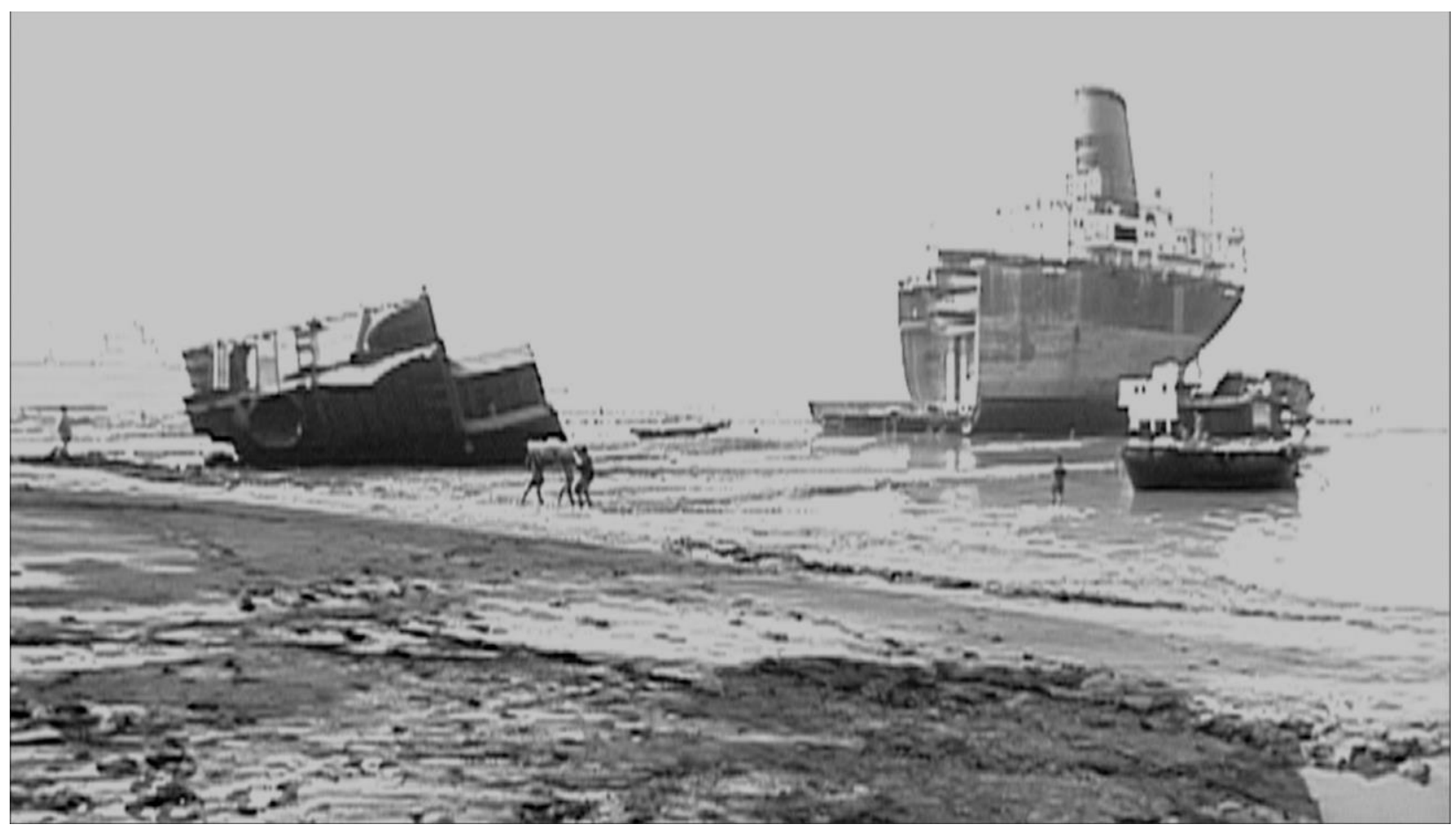

Baichwal, J. (2006) mm. 39:12.

No debería sorprendernos, entonces, que tanto Burtynsky como Baichwal eligieran los parámetros de representación que se asocian a esta categoría para sostener su argumento, para mostrar sin necesidad de explicar nada más. Por otra parte, en las palabras con las que el fotógrafo explica su obra -"nos hacen conscientes", "mostrar su escala" - nos parece posible encontrar una conexión con el imperativo de "hacer ver lo que hace ver", presentado por Jean-Francois Lyotard en su ensayo "Lo sublime y las vanguardias" (1998). En este texto, Lyotard desarrolla una definición de lo sublime a partir del manifiesto “The Sublime is Now” (1948) del pintor Barnett Newman. “¿Qué quiere decir ese 'now'?" Se pregunta Lyotard, y especula: quiere decir que lo sublime habla siempre de lo indeterminado; mejor dicho, presenta lo indeterminado, ya que es eso de lo que no se puede hablar, porque no hay palabras apropiadas para definirlo. "Now" representaría el momento suspendido en que se espera que suceda algo, pero al mismo tiempo se lo interroga "¿sucede algo?". "Olvidan esta posibilidad" sostiene Lyotard, "que no suceda nada, que falten las palabras..." (1998, p. 97): 
Con la estética de lo sublime, lo que está en juego en las artes de los siglos XIX y XX es convertirse en testigos de lo que hay de indeterminado [...] Estas sensaciones elementales están ocultas en la percepción corriente que se mantiene bajo la hegemonía de la manera de mirar habitual o clásica. No son accesibles al pintor ${ }^{12}$, y por lo tanto suceptibles de que él las restituya, sino al precio de una ascesis interior que libera al campo perceptivo y mental de los prejuicios inscriptos incluso en la visión misma. Si lo observado, por su lado, no se somete a una ascesis complementaria, el cuadro seguirá siendo para él un sinsentido impenetrable [...] El reconocimiento de las instituciones reguladoras [...] crítica, gusto, tiene poca importancia frente al juicio que el pintor investigador y sus pares emiten sobre el éxito obtenido por la obra con respecto a lo que verdaderamente está en juego: hacer ver lo que hace ver, y no lo que es visible (p. 106).

Barnett Newman, el pintor que origina el estudio de Lyotard con su manifiesto de 1948, proclama que su búsqueda artística consiste a su vez en liberar la mirada de cualquier idea de belleza e incluso de forma. Así, argumenta que sólo en América, que no estaba aprisionada por su historia, pudo surgir un arte plástico capaz de reencontrarse con lo sublime, es decir, que lograra la auténtica destrucción de la belleza (sinónimo de la forma perfecta). Sin embargo, en un mundo despojado de sus grandes mitos, la única manera de recuperar lo sublime era en la abstracción:

[...] nos estamos liberando de los impedimentos de la memoria, de la asociación, de la nostalgia, la leyenda, el mito, o los que sean que hayan sido los instrumentos de la pintura occidental europea [...] La imagen que producimos es la evidente en sí misma de la revelación, real y concreta, que puede ser comprendida por quienquiera que la vea sin las nostálgicas lentes de la historia ${ }^{13}$ (1999, p. 574).

12 Y aquí podríamos agregar: ni al realizador de cine.

13 "We are freeing ourselves of impediment of memory, association, nostalgia, legend, myth, or what have you, that have been the devices of Western European painting. [...] The image we produce is the self-evident one of revelation, real and concrete, that can be understood by anyone who will look at it without the nostalgic glasses of history" (Newman, 1999, p. 574). 
En su polémico ensayo de 1961, "The Abstract Sublime", Robert Rosenblum retoma a su vez las ideas de Newman, pero vincula lo sublime abstracto a los paisajes de los románticos ingleses y alemanes. De este modo, Rosenblum recupera la tradición que Newman aclamaba ausente en su arte: "durante la era romántica, las sublimidades de la naturaleza eran pruebas de la divinidad; hoy, esas experiencias sobrenaturales son transmitidas por el medio abstracto de la pintura solamente"14(2010, p. 278). De lo sublime romántico, presente en el espíritu panteísta de la naturaleza, a lo sublime abstracto, que abandona la representación de paisajes por los colores puros, pero que conserva su efecto estético, consistente en enfrentar a las personas con un poder ilimitado, más allá de lo concebible por la imaginación (lo sublime dinámico). El efecto estético que consta de "hacer ver lo que hace ver" del que hablara Lyotard, la revelación que cae sobre los espectadores como "el golpe de un rayo" de la que hablara Longino.

De este modo, Rosenblum recupera la tradición repudiada por Newman, y con ella la continuidad de la estética de lo sublime durante el siglo XX: si Kant quitó lo sublime de la naturaleza y lo depositó en el que devendría el contemplador romántico, parado sobre el abismo en completa calma, Newman (y los demás artistas del expresionismo abstracto) expulsó al contemplador fuera del cuadro y lo puso frente a la potencia de la imagen abstracta. Pero el efecto estético buscaría ser el mismo, es una imagen sublime cuyo fin es el de la revelación: el de romper con prejuicios, preconceptos, modos cotidianos de mirar, forzar los límites de lo imaginable... ¿podría entonces pensarse que lo sublime es devuelto a las imágenes de la naturaleza por Burtynsky y Baichwal en los albores del siglo XXI, para mostrar la potencia destructiva de ese contemplador kantiano?

Al inicio de este ensayo hablamos de la importancia de la presencia de la naturaleza en las ruinas. Para autores como Woodward, en este asedio de la vegetación a las estructuras abandonadas se encuentra el principal valor estético de las ruinas, representan la "mano del tiempo, la contienda del individuo con el universo" (2002, p. 69). Así también, recuperamos los trabajos de Masiello y Huyssen quienes sostienen que es la presencia materializada del paso del tiempo lo que define su

14 "During the Romantic era the sublimities of nature gave proof of the divine; today, such supernatural experiences are conveyed through the abstract medium of paint alone" (Rosenblum, 2010, p. 278). 
sentido último: las ruinas como manifestación de un tiempo múltiple, de la coexistencia de un pasado recuperable a medias y de la profecía de una futura destrucción. En esta conjugación de la naturaleza y el tiempo podemos leer vestigios de la idea kantiana de lo sublime: la contemplación de un paisaje en ruinas despertaría en el espectador la consciencia de un poder destructivo que supera sus posibilidades de resistencia, así como superó las de los que vivieron antes que él. En el ensayo audiovisual de Baichwal, así como en las fotografías de Burtynsky, estas ideas se conjugan de forma diferente: ya no son las raíces de los árboles las que destrozan los cimientos de las antiguas ciudades, sino sus propios habitantes, empobrecidos, quienes cobrarán por ladrillo retirado cuando la represa de Las Tres Gargantas inunde sus antiguos barrios; ya no es una ola tras otra las que corroen las quillas de los barcos, sino, nuevamente, la acción humana: esos diminutos muchachos indios, apenas humanos en sus minúsculas dimensiones, que acarrean las inmensas placas de acero mientras cantan.

Burtynsky se pregunta al inicio del film: “¿Hay algún modo en el que pueda hablar realmente de la naturaleza y compartir alguna opinión acerca de lo que representa?" (Baichwal, 2006, mm. 05:34-05:38). Hacia el final, se responde:

Si dijera: "esto es algo terrible que le estamos haciendo al planeta". Entonces la gente podría estar de acuerdo o no. Al no decirlo, sino que uno lo ve, hago que la gente pueda ver algo que nunca ha visto y que miren su mundo de un modo diferente. [...] No es una simple cuestión de lo que está bien o está mal. Exige todo un nuevo modo de pensar (mm. 79:2380:09).

Creemos que en esta elección de mostrar y no decir, de mostrar lo sublime en la naturaleza (aunque en este caso sea la sublime devastación de la naturaleza y sus habitantes) se encuentra profundamente arraigado este potencial retórico de las imágenes sublimes, que conjugan lo ético y lo estético para forzar la imaginación de los espectadores más allá de sus límites cotidianos, les "exige todo un nuevo modo de pensar" y de mirar. 


\section{Conclusiones: el ensayo como forma}

Sólo el siglo postkantiano perdió junto con la violencia de lo real la osadía del intento. Por eso el ensayo se ha trocado de una forma de la gran filosofía a una forma menor de la estética, bajo cuyo aspecto, pese a todo, huyó a cobijarse una concreción de la interpretación de la cual no dispone hace ya mucho la filosofía propiamente dicha [...] Si al arruinarse toda seguridad en la gran filosofía el ensayo se mudó allí, si al hacerlo se vinculó con las interpretaciones limitadas, perfiladas y nada simbólicas del ensayo estético, ello no me parece condenable en la medida en que escoja correctamente sus objetos: en la medida en que sean reales. Pues el espíritu no es capaz de producir o captar la totalidad de lo real; pero sí de irrumpir en lo pequeño, de hacer saltar en lo pequeño las medidas de lo meramente existente (Adorno, 1994, p. 102).

Esto escribió Adorno en su temprano ensayo "La actualidad de la filosofía" (1994), adelantando lo que desarrollaría más adelante en su insoslayable estudio "El ensayo como forma" (2003). En este último, Adorno reclama la forma literaria, estética, del ensayo como la más apropiada para el conocimiento filosófico debido a su desarrollo libre, inacabado, donde se conjugan lo poético y la realidad material. Además, el ensayo sería "la forma crítica par excellence; y ciertamente, en cuanto crítica inmanente de las obras espirituales, en cuanto confrontación de lo que son con su concepto, crítica de la ideología" (2003, p. 29). Para Adorno, la forma del ensayo es la de la experimentación de quien, sin un objetivo preestablecido, se abandona al juego y al intento, a ver cómo se presenta un fenómeno cuando se lo entreteje en nuevas relaciones, cuando se lo desarma y rearma en un medio estético.

A partir de lo desarrollado anteriormente, nos parece posible encontrar un eco de estas ideas adornianas, de esta propuesta teórica y metodológica acerca de cómo llegar a un conocimiento de lo real en las obras del espíritu, en el género fílmico del cine ensayo y, muy particularmente, en la obra estudiada. Después de todo, como en su forma literaria, es la dialéctica propia de las imágenes y las palabras la que compone el cine ensayo contemporáneo, "estos textos incisivos, contundentes, en los que una afilada ironía juega al escondite con la poesía" (Bazin, 2012, p. 1).De hecho, este texto 
fundacional de André Bazin establece el vínculo directamente, al sostener que se trata de "un ensayo documentado por el film. La palabra que importa aquí es 'ensayo', entendida en el mismo sentido que en literatura: [...] a la vez histórico y político, aunque escrito por un poeta" (p. 2).

Por su parte, Walter Benjamin, en sus trabajos incompletos Tesis sobre la historia (2008) y el fragmentario Libro de los pasajes (2005), propone una metodología novedosa para la filosofía de la historia: reclama para sí la técnica del montaje, del citar sin comillas, del comentario. Reclama para sí una historia escrita a partir de imágenes ${ }^{15}$ que conjuguen en sí mismas el entonces y el ahora, que hagan estallar el continuo devenir hacia la destrucción.

No podemos evitar vislumbrar un eco de estas ideas benjaminianas en Manufactured Landscapes, donde las imágenes de la devastación contemporánea del paisaje que componen el film, aunque documentales, se configuran artísticamente -remitiendo a la estética de lo sublime- y se inscriben, por un lado, con los datos científicos acerca de esta misma devastación y, por el otro lado, con las reflexiones subjetivas de Burtynsky, el fotógrafo, sobre su propia obra.

En las fragmentarias imágenes las esencias aparecen en forma concreta, pero es la construcción filosófica la que, aun invisible, da apoyo y coherencia al todo. Cuando Benjamin calificaba al montaje de progresista porque "interrumpía el contexto en el que se insertaba", se refería a su dimensión crítica, destructiva (la única que la observación de Adorno reconoce). Pero el propósito del proyecto de los Pasajes era también el de diseñar una dimensión

15 Nos referimos al concepto de "imagen dialéctica" delineado por Walter Benjamin a lo largo de su obra, pero particularmente en sus trabajos mencionados. La "imagen dialéctica", para Benjamin, debería ser el objeto de estudio propio de la historia. "La historia se descompone en imágenes, no en historias" (2005, p. 478) escribió Benjamin en el convoluto " $\mathrm{N}$ " de su Libro de los pasajes. Pero no se trata de una imagen cualquiera. La imagen dialéctica es la que hace estallar el continuum de la historia como golpeado por un rayo, ya que condensa en sí misma, como una mónada o una constelación, el pasado y el ahora mismo (jetztzeit). Benjamin sostiene que si bien la relación entre el pasado y el presente es continua, no ocurre lo mismo con el "entonces" y el "ahora", porque el momento del ahora contiene en sí mismo el del entonces, y este último sólo adquiere legibilidad a partir de su conexión con el jetztzeit. La relación entre ambos es discontinua, se condensa en una imagen más que en una narración; y estas imágenes de la historia, explica Benjamin, sólo llegan a ser dialécticas cuando alcanzan su "momento de cognoscibilidad", es decir, cuando el observador crítico las encuentra cargadas del momento del ahora mismo. Entonces, son capaces de destrozar el continuo devenir en el que se encontraban. Porque las imágenes dialécticas de la historia siempre están en peligro de pasar y perderse para siempre si no somos capaces, desde el ahora, de reconocernos en ellas y tomar responsabilidad por lo pasado. 
constructiva del montaje, como la única forma en la que puede erigirse la filosofía moderna (Buck-Morss, 2001, p.94).

Tal como explica Susan Buck-Morss, en Manufactured Landscapes las imágenes documentales se insertan en un comentario a la vez filosófico-crítico y poético que les da coherencia, pero que a la vez interrumpe el contexto del que provenían. Es decir, provoca que el espectador entienda esas imágenes como "re-contextualizadas", provenientes de otro lugar, desarmadas y rearmadas en un ámbito estético en el que cobran sentido de nuevo. Del mismo modo, el montaje benjaminiano no busca una síntesis entre signo y referente, sino lo contrario: que se vean las junturas, que se vea el artificio, que se vea la interrupción entre la imagen y el contexto en el que se inserta: ahí reside la lectura crítica, la imagen dialéctica, donde opera el entonces y el ahora mismo.

Al principio de esta presentación, citamos a Andreas Huyssen cuando sostiene que nuestra sociedad contemporánea ya no puede apreciar estéticamente las ruinas, porque es una sociedad del reciclaje o la destrucción. Además, Huyssen toma como concepto clave de su análisis el de "nostalgia". Las ruinas, argumenta, especialmente las ruinas del siglo XX -como las que protagonizan la obra estudiada-, despiertan nuestra nostalgia porque nos recuerdan una época en la que era imaginable un futuro mejor... ¿qué fue de ese futuro? Yace en ruinas. Y en el siglo XXI, continúa Huyssen (de modo similar a Masiello y Woodward), las ruinas son mayormente atractivos turísticos donde casi no se reflexiona crítica o poéticamente (como Shelley).

Pero las ruinas que protagonizan el ensayo audiovisual de Baichwal no figuran en ninguna guía de viaje. Más bien, son detritus de la historia que se quiere olvidar. Son calvarios. Sus habitantes son los sepultureros olvidados de la Fortuna... y quizás justamente por eso, realizadores como Baichwal filman estas ruinas de nuestro tiempo. Quizás las filman para recordarnos que están ahí (aunque no queramos verlas, ni pensarlas, ni imaginarlas) y que a los gritos reclaman que todas las cosas son perecederas, que la historia acumula ruina sobre ruina a nuestras espaldas.

Al mismo tiempo, como las imágenes dialécticas bejaminianas, estas obras audiovisuales "están cargadas de tiempo hasta estallar" (Benjamin, 2005, p.465). Los paisajes manufacturados de 
Baichwal, como argumentamos, hacen estallar el continuum visual de las imágenes de la vida cotidiana con el "golpe de rayo" de Longino. Estos paisajes audiovisuales y fotográficos toman el potencial retórico de lo sublime para "hacer ver lo que hace ver": una imagen, una toma, que muestra el paisaje de nuestro tiempo en toda su devastación.

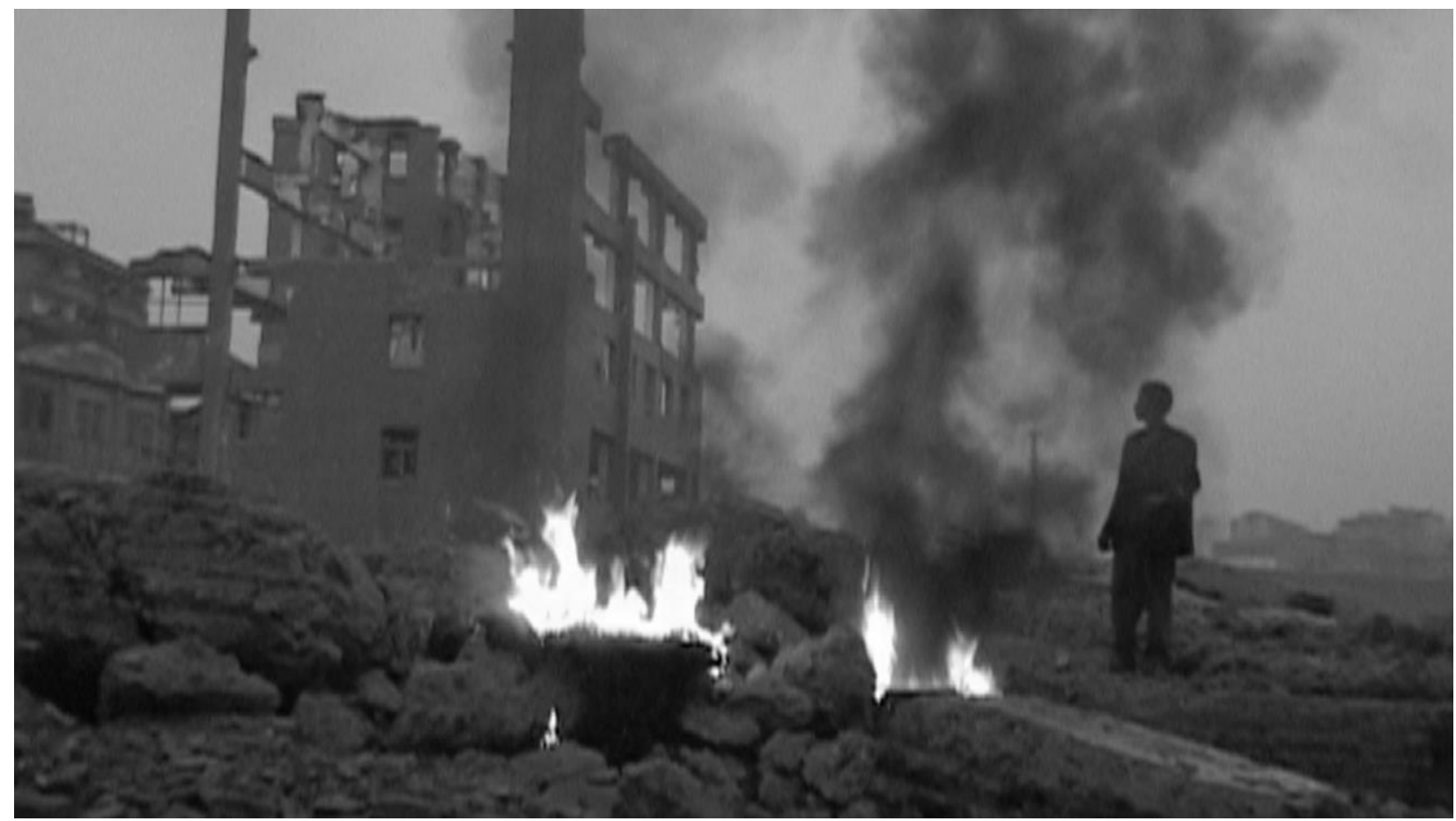

Baichwal, J. (2006) mm. 62:57.

\section{Referencias:}

Adorno, T. (1994). Actualidad en filosofía. La idea de historia natural. En Actualidad en filosofía (Traductor Arantegui J. L.). Barcelona: Altaya, pp. 73-135.

Adorno, T. (2003). El ensayo como forma. En Notas sobre literatura. Obra completa, 11 (Traductor Brotons, A.). Barcelona: Akal, pp. 11-34.

Baichwal, J. (2006). Manufactured Landscapes. Canadá: Foundry Films, National Film Board of Canada (NFB). 
Bazin, A. (30 de julio de 2012) “Chris Marker (1). Lettre de Sibérie". Cinéfilo. [Versión electrónica]. Recuperada de https://cinefilobar.wordpress.com/2012/07/30/chris-marker-1-lettre-desiberie-por-andre-bazin/

Benjamin, W. (2005). El libro de los pasajes (Traductores Fernández, L., Herrera, I. y Guerrero, F.). Madrid: Akal.

Benjamin, W. (2008). Tesis sobre la historia y otros fragmentos. Bolívar Echeverría (Ed.). Ciudad de México: Ítaca.

Boetzkes, A. (2010). Waste and the Sublime Landscape. Canadian Art Review. 35(1), 22-31.

Buck-Morss, S. (2001). Dialéctica de la mirada. Walter Benjamin y el proyecto de los Pasajes (Traductora Rabotnikof, N.). Madrid: La balsa de la Medusa.

Burke, E. (2014). A Philosophical Enquiry into the Origins of Our Ideas of the Sublime and Beautiful. [Versión electrónica] Recuperada de http://ebooks.adelaide.edu.au/b/burke/edmund/sublime/index.html

Huyssen, A. (2006). Nostalgia for Ruins [Versión electrónica]. Grey Room. 23, 6-21. Recuperada de http://www.jstor.org/stable/20442718

Kant, I. (2005). Critica del Juicio (Traductor Rovira, J.). Buenos Aires: Losada.

“Longino" (1979). Sobre lo Sublime (Traductor García, J.). Madrid: Gredos.

Lyotard, J. F. (1998). Lo sublime y la vanguardia. En Lo inhumano. Charlas sobre el tiempo (Traductor Pons, H.). Buenos Aires: Manantial, pp. 95-111.

Masiello, F. (2008). Los sentidos y las ruinas. Iberoamericana. VII(30), 103-112.

Newman, B. (1999). The Sublime is Now. En, Art in Theory 1900-1990. Oxford: Blackwell, pp.572-574.

Rosenblum, R. (2010). The Abstract Sublime. En S. Morley (Ed.), The Sublime. London: White chapel Gallery y The MIT Press, pp.108-113.

Sebald, W. G. (2002, 4 de noviembre). A Natural History of Destruction [Versión electrónica]. The New Yorker, pp. 66-77. 
Shelley, P. B. (1914). Prometheus Unbound. A Lyrical Drama in Four Acts. En T. Hutchinson (Ed.), The Complete Poetical Works. London, [etc.]: Humphrey Milford, Oxford University Press, pp. 201266.

Shelley, P. B. (2009). Prometeo Liberado (Traductor Valero, A.). Madrid: Hiperión.

Woodward, Ch. (2002). In Ruins. Croydon: Vintange. 